\title{
Association of vitamin D receptor expression with inflammatory changes and prognosis of asthma
}

\author{
YANHUA CHEN and TONGBAI XU \\ Respiratory Department, Tianjin Hospital of ITCWM Nankai Hospital, Tianjin 300000, P.R. China
}

Received December 28, 2017; Accepted July 2, 2018

DOI: $10.3892 /$ etm.2018.6867

\begin{abstract}
The expression level of vitamin D receptor in patients with asthma was investigated to study the association between vitamin $\mathrm{D}$ receptor and inflammatory changes in asthma. Thirty patients with bronchial asthma treated in the Tianjin Hospital of ITCWM Nankai Hospital were selected as the experimental group, while 30 healthy individuals were selected as the control group. The mRNA expression level of vitamin D receptor in blood was detected via reverse transcription-quantitative polymerase chain reaction (RT-qPCR). The protein expression level of vitamin $\mathrm{D}$ receptor in blood was detected via western blot analysis and the levels of inflammatory factors were detected via enzyme-linked immune sorbent assay (ELISA). Correlations between the expression level of vitamin D and inflammatory factors were studied via Pearson's analysis. Finally, the prognoses of patients were recorded and analyzed. The results showed that the mRNA and protein expression levels of vitamin D receptor in the experimental group were significantly lower than those in control group $(\mathrm{P}<0.01)$. The content of $25-(\mathrm{OH}) \mathrm{D}_{3}$ in serum in the experimental group was significantly lower than that in the control group $(\mathrm{P}<0.01)$. The contents of interleukin- 6 (IL-6) and tumor necrosis factor- $\alpha$ (TNF- $\alpha)$ in serum in the experimental group were obviously higher than those in the control group, but the contents of IL-10 and transforming growth factor- $\beta$ (TGF- $\beta$ ) were obviously lower than those in the control group $(\mathrm{P}<0.01)$. Moreover, the correlation analysis revealed that IL-6 and TNF- $\alpha$ were negatively correlated with the expression of vitamin $\mathrm{D}$ receptor $(\mathrm{P}<0.05)$, whereas IL-10 and TGF- $\beta$ were positively correlated with the expression of vitamin $\mathrm{D}$ receptor $(\mathrm{P}<0.05)$. In conclusion, the expression of vitamin $\mathrm{D}$ receptor is positively correlated with the levels of pro-inflammatory factors. Moreover, the vitamin D receptor affects the prognosis and recovery of lung function of patients with asthma.
\end{abstract}

Correspondence to: Dr Yanhua Chen, Respiratory Department, Tianjin Hospital of ITCWM Nankai Hospital, 6 Changjiang Road, Nankai, Tianjin 300000, P.R. China

E-mail: youbang0915@163.com

Key words: asthma, vitamin D receptor, inflammation, prognosis

\section{Introduction}

Asthma is a chronic airway inflammatory disease, which is mainly regulated by airway inflammatory cells and dominated by bronchial asthma $(1,2)$. The incidence of asthma is affected jointly by the environment, genetics and immune function, whose main clinical manifestations are recurrent asthma and cough. Due to changes in time and solar terms, it occurs regularly, and is often aggravated at night and in the early morning. This means that for children who are sensitive, an asthma attack may occur, seriously affecting the development of children $(3,4)$.

Previous findings suggest that the inflammatory response produced after lymphocyte activation and airway infiltration is an important mechanism of asthma $(5,6)$. Vitamin D is a steroid derivative with a strong effect of regulating blood calcium and bone metabolism. Research data have shown that vitamin D can also regulate the hormone level of human immunity (7). Ali and Nanji (8) found that the level of serum vitamin D is closely related to the incidence of asthma in children, and the level of vitamin D also affects the lung function of children. However, the correlations of vitamin D receptor (VDR) level in asthma patients with the pathogenesis of asthma and airway inflammation have not been reported yet.

This study aimed to clarify the role of VDR in asthma by comparing the level of VDR between asthma patients and healthy controls, and study the relationships of VDR with the prognoses of inflammation and asthma to provide new ideas for a clearer understanding and effective treatment of asthma.

\section{Patients and methods}

Patients and grouping. Patients with bronchial asthma treated at the Tianjin Hospital of ITCWM Nankai Hospital (Tianjin, China) from March, 2015 to March, 2016 were selected and screened according to the criteria in the Guidelines on Diagnosis and Prevention of Children's Bronchial Asthma (9). A total of 30 patients meeting the criteria were selected as the experimental group, while 30 healthy individuals were selected during the same period as the control group. The experimental group comprised 16 males and 14 females, aged 8-16 years. The control group comprised 15 males and 15 females, aged 9-16 years. There were no statistically significant differences in age and sex between the two groups. Inclusion criteria of bronchial asthma patients were: i) patients 
with recurrent asthma induced by exercise and other factors; ii) the expiratory phase-based wheezing rale could be heard in lungs during the onset; iii) patients who did not take other drugs and vitamin D-related drugs during the same period. Patients with other consumptive diseases were excluded from the study. The study was approved by the Ethics Committee of Tianjin Hospital of ITCWM Nankai Hospital, and the patients had complete clinical and pathological data and the complete therapeutic regimen. Informed consents were signed by the parents and/or guardians of the patients.

Detection of VDR expression in vivo via reverse transcription-quantitative polymerase chain reaction (RT-PCR). Fasting blood ( $5 \mathrm{ml}$ ) was drawn from the patients and controls and centrifuged at $2,300 \mathrm{x}$ g for $10 \mathrm{~min}$ at $4^{\circ} \mathrm{C}$ to collect the supernatant. After the TRIzol reagent (volume ratio of 1:1) (TRIzol kit; Thermo Fisher Scientific, Inc., Waltham, MA, USA) was added, chloroform was added and the mixture was repeatedly shaken 10 times, followed by centrifugation at $11,000 \mathrm{x} \mathrm{g}$ for $10 \mathrm{~min}$ at $4^{\circ} \mathrm{C}$. The supernatant was transferred to a new centrifuge tube and isopropanol was added. After centrifugation at $9,060 \times \mathrm{g}$ for $10 \mathrm{~min}$ at $4^{\circ} \mathrm{C}$, the supernatant was discarded. Then, $1 \mathrm{ml}$ freshly-prepared $75 \%$ ethanol was added, and the mixture was repeatedly shaken and washed, followed by centrifugation at $11,000 \mathrm{x}$ g for $10 \mathrm{~min}$ at $4^{\circ} \mathrm{C}$. The supernatant was discarded and the tube cap was opened to dry naturally at room temperature, and $50 \mu 1$ diethylpyrocarbonate (DEPC) was dissolved to obtain the RNA samples.

After the determination of $\mathrm{A}_{260} / \mathrm{A}_{280}$ and the optical density (OD) value, $10 \%$ agarose gel was used to confirm that the extracted RNA was not degraded. According to the instructions of kit, the strand of complementary DNA (cDNA) was obtained, based on which primers, Taq polymerase, Taq buffer, deoxyribonucleoside triphosphate (dNTP) mixture and double-distilled water $\left(\mathrm{ddH}_{2} \mathrm{O}\right)$ were added for PCR amplification on a PCR instrument. Finally, the products were placed on a quantitative PCR instrument to detect the mRNA expression of target genes. The size of amplified product was $233 \mathrm{bp}$, and the PCR conditions are as follows: pre-denaturation at $92^{\circ} \mathrm{C}$ for $45 \mathrm{sec}$, denaturation at $95^{\circ} \mathrm{C}$ for $5 \mathrm{sec}$, and annealing at $60^{\circ} \mathrm{C}$ for $30 \mathrm{sec}$; a total of 35 cycles. The above primer sequences were synthesized by Tiangen Biotech Co., Ltd. (Beijing, China) and the sequences are shown in Table I.

Detection of expression of related proteins via western blot analysis. Peripheral blood $(5 \mathrm{ml})$ was collected from patients in each group, and added with lysis buffer (volume ratio of $1: 1$ ), followed by centrifugation at $1,100 \times \mathrm{g}$ at $4^{\circ} \mathrm{C}$ for $10 \mathrm{~min}$. The supernatant was the total protein, and the total protein concentration in the blood sample in each group was detected using the bicinchoninic acid (BCA) protein assay kit (Pierce, Rockford, IL, USA). The loading buffer was prepared according to the concentration of samples, and the total protein level in loading buffer in each group was made equal. After the gel preparation, the samples were loaded for sodium dodecyl sulfate polyacrylamide gel electrophoresis (SDS-PAGE) under the constant voltage of $80 \mathrm{~V}$ for $100 \mathrm{~min}$. The protein was transferred onto a polyvinylidene fluoride (PVDF) membrane (IPVH00010; Millipore, Billerica, MA, USA) at $90 \mathrm{~V}$ for $100 \mathrm{~min}$. The target bands were cut and sealed
Table I. PCR primers.

Gene name Primer sequences

VDR

F: 5'-TCGTATGGACGGAAGTACAGG-3'

R: 5'-AAGACTGGTTGGAGCGTAACA-3'

Glyceraldehyde-3- F: 5'-GGTGAAGGTCGGTGTGAACG-3'

phosphate R: 5'-CTCGCTCCTGGAAGATGGTG-3'

dehydrogenase

(GAPDH)

PCR, polymerase chain reaction; VDR, vitamin D receptor; F, forward; $\mathrm{R}$, reverse.

in $5 \%$ skimmed milk powder for $2 \mathrm{~h}$, after which the mouse anti-human VDR and GAPDH polyclonal antibodies (1:800; cat. nos. SAB1406580 and SAB1405848, respectively; SigmaAldrich; Merck KGaA, Darmstadt, Germany) were incubated at $4^{\circ} \mathrm{C}$ overnight. The bands were washed with phosphatebuffered saline (PBS) 3 times (5 min each time) and incubated with the rabbit anti-mouse horseradish peroxidase-conjugated secondary polyclonal antibody (1:1,000; cat. no. A9044; Sigma-Aldrich; Merck KGaA) at room temperature for $2 \mathrm{~h}$. The bands were washed again with PBS 3 times and added with the electrochemiluminescence (ECL) solution to obtain the image using the fluorescence developing technique. The relative expression level of VDR was presented as VDR/ GAPDH.

Detection of contents of inflammatory factors and 25-hydroxyvitamin $D_{3}\left[25-(\mathrm{OH}) D_{3}\right]$ in vivo via enzymelinked immunosorbent assay (ELISA). Fasting blood $(5 \mathrm{ml})$ was drawn from patients in each group and centrifuged to obtain the serum. The contents of interleukin-6 (IL-6), IL-10, transforming growth factor- $\beta$ (TGF- $\beta)$, tumor necrosis factor- $\alpha(\mathrm{TNF}-\alpha)$ and $25-(\mathrm{OH}) \mathrm{D}_{3}$ were detected using the ELISA kit: The standard curves of IL- 6 , IL-10, TGF- $\beta$, TNF- $\alpha$ and $25-(\mathrm{OH}) \mathrm{D}_{3}$ were drawn using the supporting standard samples in the ELISA kit, and the above standard curves were used to quantify the corresponding proteins. Then, $100 \mu \mathrm{l}$ serum samples in each group were diluted 10 -fold using the sample diluent that was added into the sample wells, and the plate was sealed with the sealing membrane for reaction under the constant temperature at $37^{\circ} \mathrm{C}$ for $60 \mathrm{~min}$. The liquid in the plate was patted dry and added with the corresponding biotinlabeled antibody for reaction at $37^{\circ} \mathrm{C}$ for $60 \mathrm{~min}$. After that, the liquid in the plate was patted dry again and washed with liquid 3 times ( 1 min each time). Then, $100 \mu 1$ avidin-peroxidase complex was added for reaction at $37^{\circ} \mathrm{C}$ for $30 \mathrm{~min}$. The liquid in the plate was patted dry again 5 times ( 2 min each time), and $100 \mu \mathrm{l}$ of stop buffer was added to terminate the reaction. The OD value of each well was measured at $450 \mathrm{~nm}$ using a microplate reader (BioTek Instruments, Inc., Winooski, VT, USA), and the serum IL-6, IL-10, TGF- $\beta$, TNF- $\alpha 25-(\mathrm{OH}) \mathrm{D}_{3}$ levels were calculated using the standard curve.

Determination of lung function. The lung function of patients in each group was detected using an EasyOne Spirometer 
A

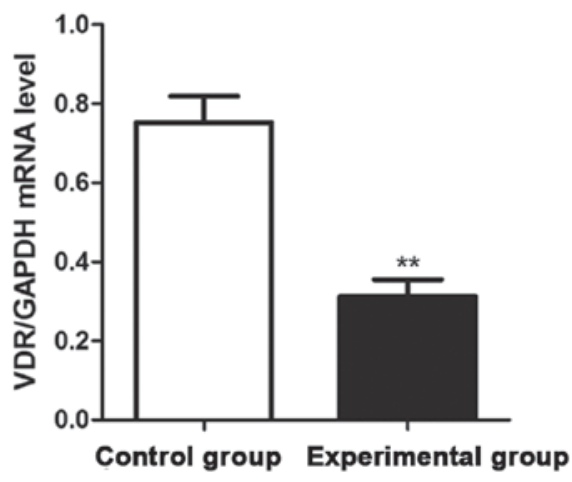

B

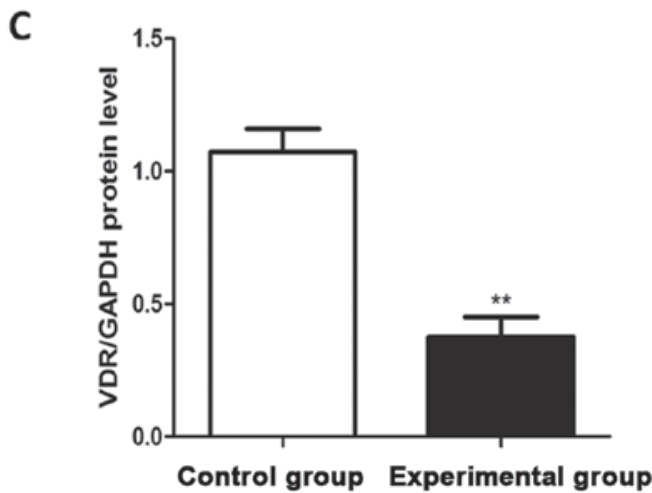

Figure 1. Detection of vitamin D receptor (VDR) expression level in each group via reverse transcription-quantitative PCR. (A) mRNA expression level of VDR; (B) vitamin D protein bands; (C) protein expression level of VDR. The mRNA and protein expression levels of VDR in experimental group are significantly lower than those in control group $\left({ }^{* *} \mathrm{P}<0.01\right)$.

Table II. General data of patients in each group.

\begin{tabular}{lccc}
\hline & Experimental group & Control group & P-value \\
\hline $\begin{array}{l}\text { Sex } \\
\text { (male/female) }\end{array}$ & $16 / 14$ & $15 / 15$ & $>0.05$ \\
Age (years) & $13.7 \pm 3.9$ & $14.1 \pm 2.8$ & $>0.05$ \\
BMI & & & \\
Normal & 21 & 20 & $>0.05$ \\
Overweight & 5 & 7 & $>0.05$ \\
Obese & 4 & 3 & $>0.05$ \\
\hline
\end{tabular}

BMI, body mass index.

lung function apparatus (NDD, Zurich, Switzerland) in the Pneumology Department of Tianjin hospital. The following parameters of patients in each group were recorded to evaluate the lung function: the percentage of forced vital capacity in predicted value ( $\mathrm{FVC} \%)$, the percentage of forced expiratory volume in $1 \mathrm{sec}$ in predicted value (FEV1\%), and 25\% peak expiratory flow (PEF25).

Assessment of asthma prognosis. Following treatment with the same regimen for 1 year, the prognosis of asthma patients in each group was evaluated using the child asthma control test (C-ACT) questionnaire with a total score of 27 points. Score <19 points: no asthma control; score 19-22 points: partial control of asthma; score $\geq 23$ points, full control of asthma.

Statistical analysis. The data in this study are presented as mean \pm standard deviation and analyzed using Statistical Product and Service Solutions (SPSS) 19.0 software (SPSS Inc., Chicago, IL, USA). The t-test was used for the intergroup comparison, Chi-square test was used for the enumeration data, and analysis of variance was used for the comparison among groups. The homogeneity test of variance was performed; if the variance was homogeneous, Bonferroni method was used for the pairwise comparison; if the variance was heterogeneous, Welch method was used for analysis. Dunnett's T3 method was adopted for multiple comparisons. Pearson's analysis was used for the correlation among factors. $\mathrm{P}<0.05$ suggested that the difference was statistically significant.

\section{Results}

Patient characteristics. General data, including sex, age and body mass index (BMI), of experimental group and control group were recorded in detail. The results (Table II) showed that the differences in sex, age and BMI of patients were not statistically significant between the experimental and control groups $(\mathrm{P}>0.05)$.

$m R N A$ and protein expression levels of VDR. The mRNA and protein expression levels of VDR were detected via reverse transcription-quantitative PCR and western blot analysis, respectively. The results (Fig. 1) revealed that the mRNA and 
A

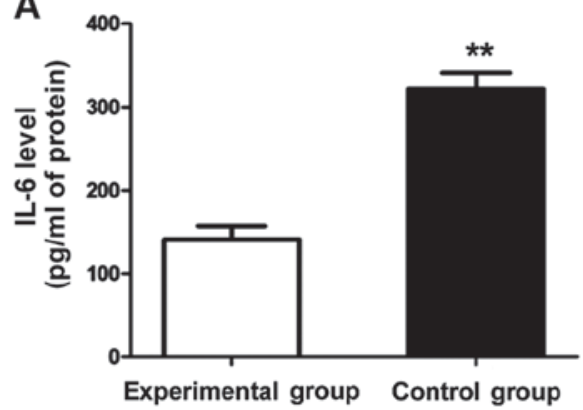

B

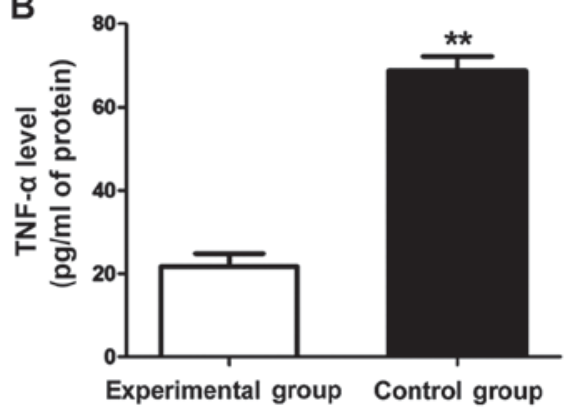

C

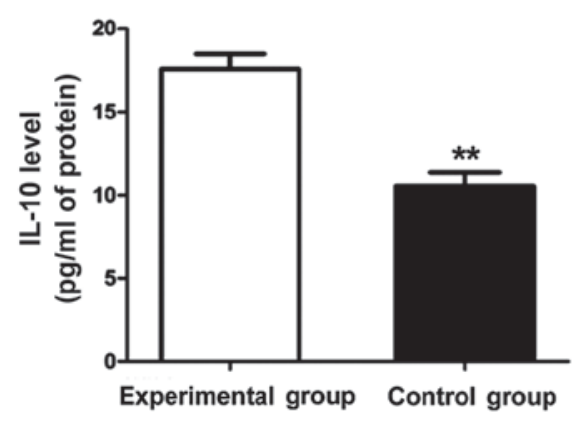

D

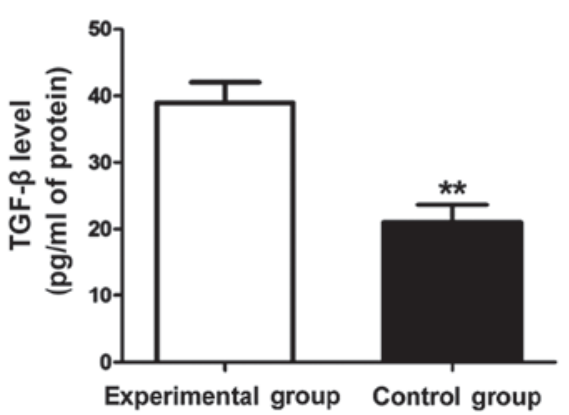

E

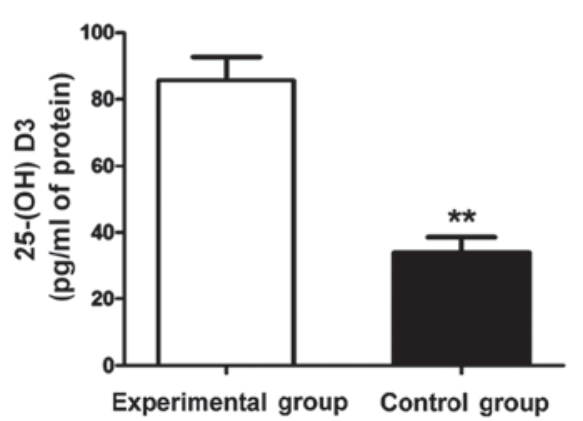

Figure 2. Detection of contents of inflammatory factors and $25-(\mathrm{OH}) \mathrm{D}_{3}$ in each group using enzyme-linked immune sorbent assay (ELISA) kit. (A) Interleukin-6 (IL-6) content; (B) tumor necrosis factor- $\alpha$ (TNF- $\alpha$ ) content; (C) IL-10 content; (D) transforming growth factor- $\beta$ (TGF- $\beta$ ) content; (E) $25-(\mathrm{OH}) \mathrm{D}_{3}$ content. The levels of IL- 6 and TNF- $\alpha$ in control group are significantly lower than those in experimental group ( $\left.{ }^{* *} \mathrm{P}<0.01\right)$; the levels of TGF- $\beta$ and IL-10 are significantly higher than those in experimental group $\left({ }^{* *} \mathrm{P}<0.01\right) ; 25-(\mathrm{OH}) \mathrm{D}_{3}$ content in experimental group is significantly lower than that in control group $\left({ }^{* *} \mathrm{P}<0.01\right)$.

Table III. Asthma control rate.

\begin{tabular}{lccc}
\hline & \multicolumn{2}{c}{ High or normal } \\
expression group & $\begin{array}{c}\text { Low expression } \\
\text { group }\end{array}$ & P-value \\
\hline Asthma control rate & $85.6 \%$ & $53.7 \%$ & $<0.01$ \\
\hline
\end{tabular}

protein expression levels of VDR in experimental group were significantly lower than those in control group, and the differences were statistically significant $(\mathrm{P}<0.01)$.

Contents of inflammatory factors and 25-(OH) $D_{3}$. The contents of inflammatory factors and 25-(OH) $\mathrm{D}_{3}$ in each group were detected using ELISA kit. The results (Fig. 2) showed that the contents of inflammatory factors (IL-6 and TNF- $\alpha$ ) in the control group were significantly lower than those in the experimental group $(\mathrm{P}<0.01)$, but the contents of anti-inflammatory factors (TGF- $\beta$ and IL-10) were significantly higher than those in the experimental group $(\mathrm{P}<0.01)$. Additionally, the content of $25-(\mathrm{OH}) \mathrm{D}_{3}$ in the experimental group was obviously lower than that in the control group, and the difference was statistically significant $(\mathrm{P}<0.01)$.

Analysis of correlations between inflammatory factors and $V D R$ expression level. The correlation between the inflammatory factors (IL-6, IL-10, TNF- $\alpha$ and TGF- $\beta$ ) and the VDR expression level was analyzed via Pearson's analysis. The results (Fig. 3) revealed that the VDR expression level was negatively correlated with IL- 6 and TNF- $\alpha$, but positively correlated with IL-10 and TGF- $\beta$.
Correlation between VDR expression and lung function of asthma patients. After treatment with the same regimen for 1 year, the lung function of asthma patients was detected using the lung function monitor. The results (Fig. 4) showed that $\mathrm{FVC} \%, \mathrm{FEV} 1 \%$ and PEF25 of patients in high or normal expression group were significantly higher than those of patients in low expression group, and the differences were statistically significant $(\mathrm{P}<0.01)$.

Correlation between VDR expression and prognosis of asthma. After treatment with the same regimen for 1 year, the prognosis of asthma patients in each group was evaluated using the C-ACT questionnaire, and the score of each patient was recorded. The results (Fig. 5 and Table III) showed that the C-ACT score of patients in the high or normal expression group was significantly higher than that of patients in low expression group, and the difference was statistically significant $(\mathrm{P}<0.01)$, and the asthma control rate of patients in the high or normal expression group was obviously higher than that of patients in low expression group $(\mathrm{P}<0.01)$.

\section{Discussion}

Environmental pollution problem has been aggravated annually, and a large number of dusts in the air and a variety of allergens lead to the increased incidence of bronchial asthma $(10,11)$. Bronchial asthma is mainly the immunoglobulin $\mathrm{E}(\mathrm{IgE})$-mediated type I allergic reaction, and the Th1/Th2 ratio imbalance will promote the production of $\operatorname{IgE}$, and induce and aggravate the occurrence of bronchial asthma (12). In recent years, vitamin D has been found to be an immunomodulator that can mediate the balance of Th 
A

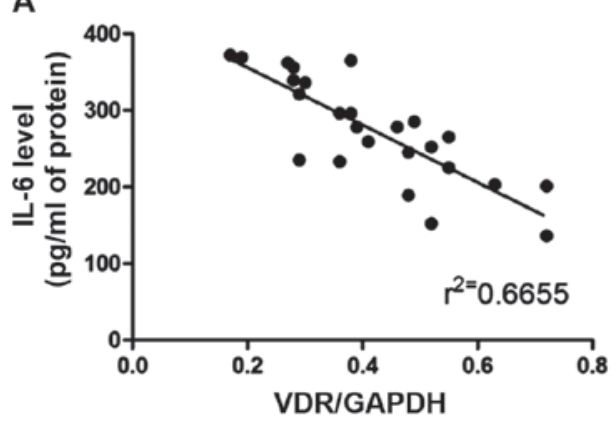

C

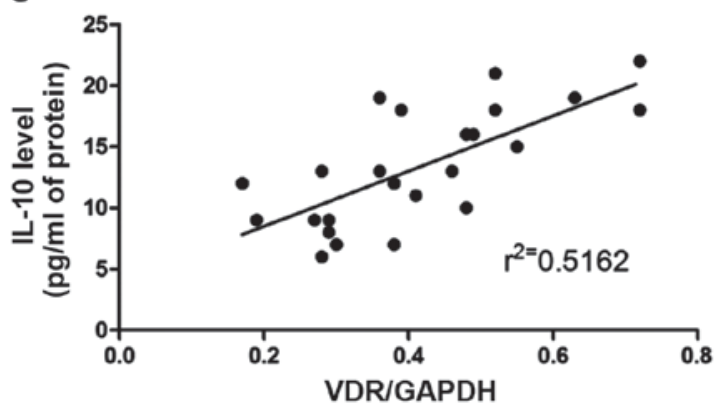

B

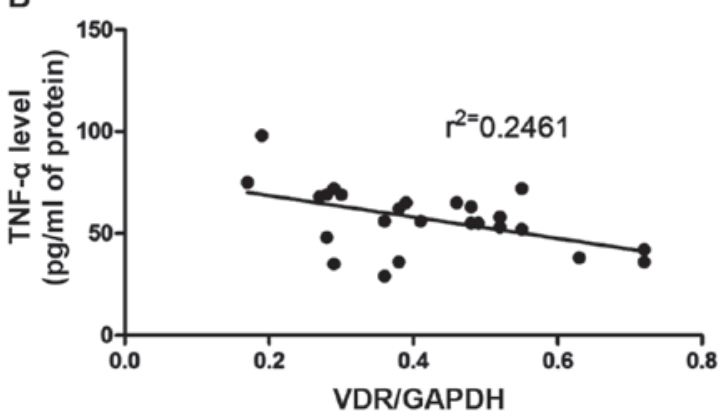

D

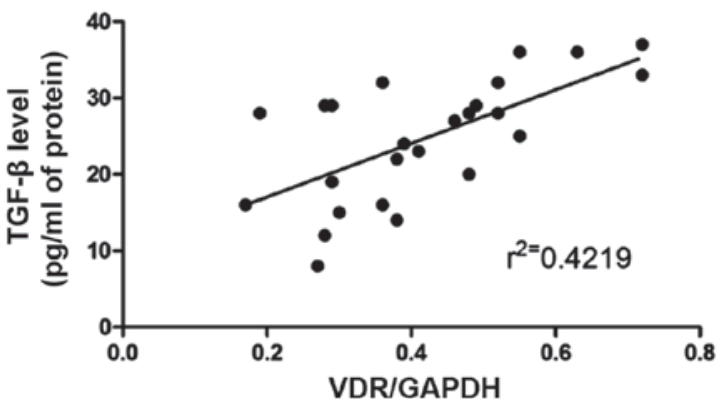

Figure 3. Analysis of correlations between inflammatory factors and vitamin D receptor (VDR) expression level. (A) Correlation between VDR and interleukin-6 (IL-6); (B) correlation between VDR and tumor necrosis factor- $\alpha$ (TNF- $\alpha$ ); (C) correlation between VDR and IL-10; (D) correlation between VDR and transforming growth factor- $\beta$ (TGF- $\beta$ ). The VDR expression level is negatively correlated with IL- 6 and TNF- $\alpha$, but positively correlated with IL-10 and TGF- $\beta(\mathrm{P}<0.05)$.
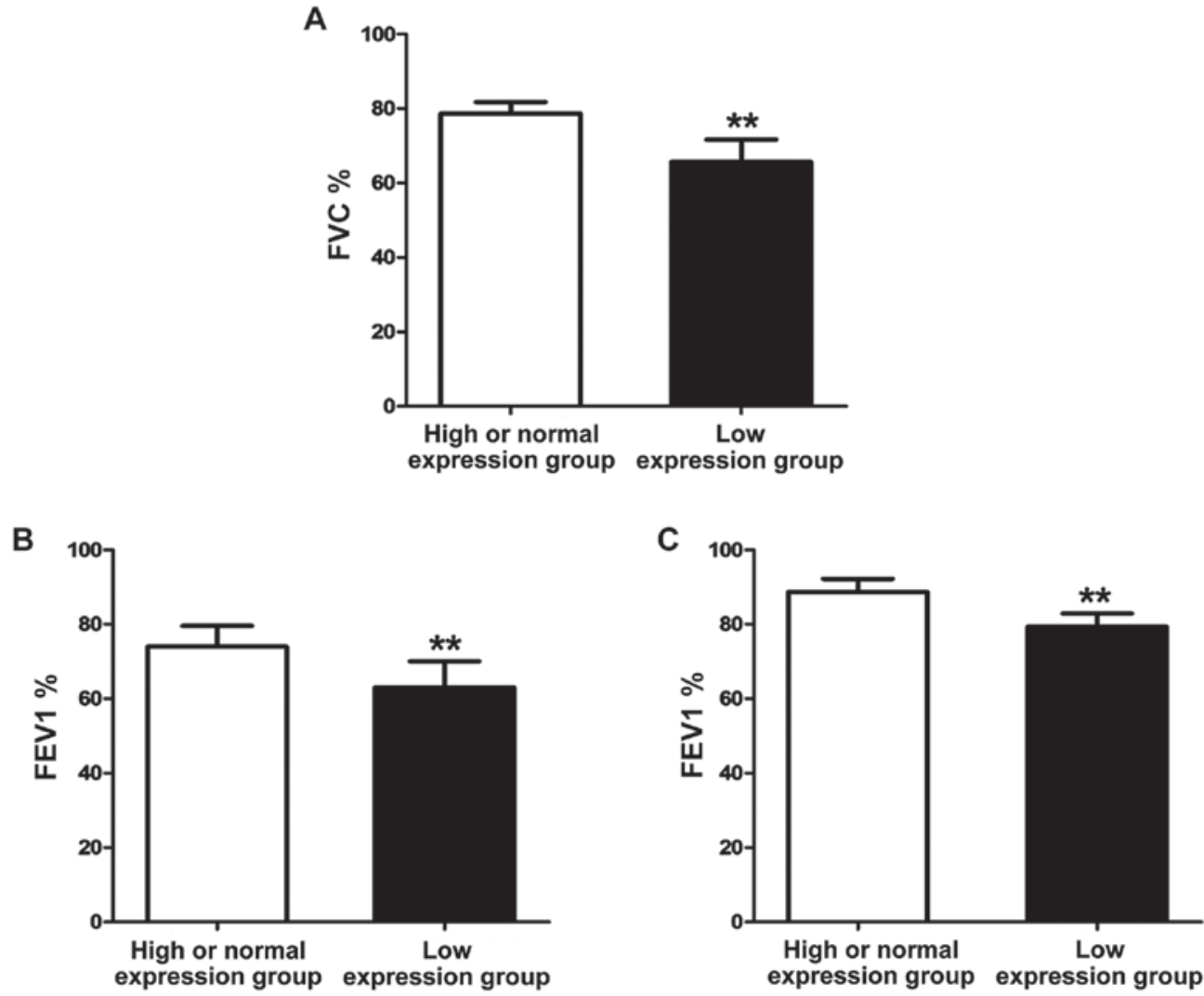

Figure 4. Comparison of lung function of patients in each group. (A) FVC\%; (B) FEV1\%; (C) 25\% peak expiratory flow (PEF25). The results show that FVC\%, FEV1\% and PEF25 of patients in high or normal expression group are significantly higher than those in low expression group $\left({ }^{* *} \mathrm{P}<0.01\right)$.

cells, thus affecting asthma (13,14). Vitamin D can also regulate a variety of signaling pathways produced by inflammatory factors, and affect the expression levels of inflammatory factors, so vitamin $\mathrm{D}$ is closely related to asthma (15). 


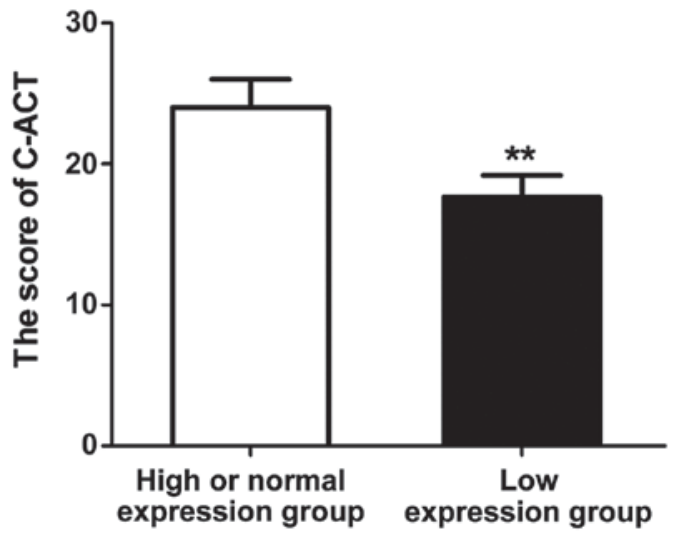

Figure 5. C-ACT score of patients in each group. The C-ACT score of patients in high or normal expression group is significantly higher than that of patients in low expression group $\left({ }^{* *} \mathrm{P}<0.01\right)$.

Studies have found that the content of active component of vitamin $\mathrm{D}, 25-(\mathrm{OH}) \mathrm{D}_{3}$, can regulate the occurrence of asthma (16). In this study, the content of $25-(\mathrm{OH}) \mathrm{D}_{3}$ in patients with bronchial asthma was detected with the normal people as the control, and it was found that the content of $25-(\mathrm{OH}) \mathrm{D}_{3}$ in asthma patients was significantly decreased, which was consistent with the finding of Jensen et al (17) that the content of $25-(\mathrm{OH}) \mathrm{D}_{3}$ in asthma children was decreased, leading to the deficiency of vitamin D. Moreover, the mRNA and protein expression of VDR in asthma patients were studied via realtime quantitative PCR and western blotting in this study. The results showed that the expression level of VDR in asthma patients was obviously decreased, suggesting that the VDR expression level can also affect the progression of asthma. Brehm et al (18) found that $25-(\mathrm{OH}) \mathrm{D}_{3}$ can exert a regulatory effect and affect the development of Th cells only when binding to VDR. Boonpiyathad et al (19) established the lipopolysaccharide-induced asthma model using VDR-knockout mice and wild-type mice, and found that the lung inflammation and asthma symptoms of VDR-knockout mice are not significant compared with those of wild-type mice. In this study, the correlations of VDR expression level in asthma patients with inflammatory factors were analyzed. The results revealed that the expression level of VDR was negatively correlated with the levels of pro-inflammatory factors, but positively correlated with the levels of anti-inflammatory factors; in other words, the VDR expression can affect the inflammatory response in the body. The study of Cantorna et al (20) found that vitamin D can regulate the immune responses in alveolar epithelial cells and alveolar macrophages and reduce the production of pulmonary inflammation, whereas $25-(\mathrm{OH}) \mathrm{D}_{3}$ can exert corresponding effects only when binding to its receptor. Besides, it was also found in this study that the expression level of VDR affected the prognosis and lung function of asthma patients, and the recovery of lung function and asthma control in patients with high VDR expression were better after treatment. The increased VDR expression level could help effectively regulate the metabolic process in the body, and the utilization level of vitamin D was also significantly increased (21).

In conclusion, the expression level of VDR is positively correlated with the levels of inflammatory factors in patients with asthma, and the expression of VDR can significantly affect the prognosis and recovery of lung function of patients with asthma.

\section{Acknowledgements}

Not applicable.

\section{Funding}

No funding was received.

\section{Availability of data and materials}

The datasets used and/or analyzed during the current study are available from the corresponding author on reasonable request.

\section{Authors' contributions}

YC wrote the manuscript. YC and TX performed PCR and western blot analysis. TX assisted in the statistical analysis. Both authors read and approved the final manuscript.

\section{Ethics approval and consent to participate}

The study was approved by the Tianjin Hospital of ITCWM Nankai Hospital (Tianjin, China). Informed consents were signed by the parents and/or guardians of the patients.

\section{Patient consent for publication}

Not applicable.

\section{Competing interests}

The authors declare that they have no competing interests.

\section{References}

1. Roxbury CR and Lin SY: Efficacy and safety of subcutaneous and sublingual immunotherapy for allergic rhinoconjunctivitis and asthma. Otolaryngol Clin North Am 50: 1111-1119, 2017.

2. Li Y, Yu Q, Zhao W, Zhang J, Liu W, Huang M and Zeng X: Oligomeric proanthocyanidins attenuate airway inflammation in asthma by inhibiting dendritic cells maturation. Mol Immunol 13: 226-232, 2012

3. Chen G, Chiang WL, Shu BC, Guo YL, Chiou ST and Chiang TL: Associations of caesarean delivery and the occurrence of neurodevelopmental disorders, asthma or obesity in childhood based on Taiwan birth cohort study. BMJ Open 3: 622-635, 2015.

4. Shin E, Lee YC, Kim SR, Kim SH and Park J: Drug signaturebased finding of additional clinical use of LC28-0126 for neutrophilic bronchial asthma. Sci Rep 5: 17784, 2015.

5. Kaur S, Gupta VK, Shah A, Thiel S, Sarma PU and Madan T: Elevated levels of mannan-binding lectin [corrected] (MBL) and eosinophilia in patients of bronchial asthma with allergic rhinitis and allergic bronchopulmonary aspergillosis associate with a novel intronic polymorphism in MBL. Clin Exp Immunol 143: 414-419, 2006.

6. Chen L, Zhong $\mathrm{N}$ and Lai K: Re-challenge with ovalbumin failed to induce bronchial asthma in mice with eosinophilic bronchitis. PLoS One 8: e75195, 2013.

7. Checkley W, Robinson CL, Baumann LM, Hansel NN, Romero KM, Pollard SL, Wise RA, Gilman RH, Mougey E and Lima JJ; PURA Study Investigators: 25-hydroxy vitamin D levels are associated with childhood asthma in a populationbased study in Peru. Clin Exp Allergy 45: 226-232, 2015.

8. Ali NS and Nanji K: A Review on the role of vitamin D in asthma. Cureus 9: e1288, 2017. 
9. Staticescu S, Chereches-Panta P, Ichim G, Valeanu M and Nanulescu MV: The value of induced sputum in the diagnosis and management of children with bronchial asthma. Clujul Med 87: 171-176, 2014.

10. Berenguer AG, Fernandes AT, Oliveira S, Rodrigues M, Ornelas P, Romeira D, Serrão T, Rosa A and Câmara R: Genetic polymorphisms and asthma: Findings from a case-control study in the Madeira island population. Biol Res 47: 40, 2014.

11. Pásztor D, Kolozsvári BL, Csutak A, Berta A, Hassan Z Kettesy BA, Gogolák P and Fodor M: Scheimpflug imaging parameters associated with tear mediators and bronchial asthma in keratoconus. J Ophthalmol 2016: 9392640, 2016.

12. Lim SY, Jo YJ and Chun EM: The correlation between the bronchial hyperresponsiveness to methacholine and asthma like symptoms by GINA questionnaires for the diagnosis of asthma. BMC Pulm Med 14: 161, 2014.

13. Luo J, Liu D and Liu CT: Can vitamin D supplementation in addition to asthma controllers improve clinical outcomes in patients with asthma? A Meta-Analysis. Medicine (Baltimore) 94 e2185, 2015.

14. Somashekar AR, Prithvi AB and Gowda MN: Vitamin D levels in children with bronchial asthma. J Clin Diagn Res 8: 4-7, 2014.

15. Augusto A: Vitamin D deficiency as a risk factor for childhood allergic disease and asthma. Curr Opin Allergy Clin Immunol 12: 86-91, 2012.

16. Jat KR and Khairwa A: Vitamin D and asthma in children: A systematic review and meta-analysis of observational studies. Lung India 34: 1787-1799, 2017.
17. Jensen ME, Mailhot G, Alos N, Rousseau E, White JH, Khamessan A and Ducharme FM: Vitamin D intervention in preschoolers with viral-induced asthma (DIVA): A pilot randomised controlled trial. Trials 17: 353, 2016.

18. Brehm JM, Schuemann B, Fuhlbrigge AL, Hollis BW, Strunk RC, Zeiger RS, Weiss ST and Litonjua AA; Childhood Asthma Management Program Research Group: Serum vitamin D levels and severe asthma exacerbations in the Childhood Asthma Management Program study. J Allergy Clin Immunol 126: 52-8.e5, 2010.

19. Boonpiyathad T, Chantveerawong T, Pradubpongsa $\mathrm{P}$ and Sangasapaviliya A: Serum vitamin D levels and vitamin D supplement in adult patients with asthma exacerbation. J Allergy (Cairo) 2016: 4070635, 2016.

20. Cantorna MT, Zhao J and Yang L: Vitamin D, invariant natural killer T-cells and experimental autoimmune disease. Proc Nutr Soc 71: 62-66, 2012.

21. Jain SK, Micinski D, Huning L, Kahlon G, Bass PF and Levine SN: Vitamin D and L-cysteine levels correlate positively with GSH and negatively with insulin resistance levels in the blood of type 2 diabetic patients. Eur J Clin Nutr 68: 1148-1153, 2014.

This work is licensed under a Creative Commons Attribution-NonCommercial-NoDerivatives 4.0 International (CC BY-NC-ND 4.0) License. 